PACS 32.15RM;

УДК 539.184

\title{
SENSING OF NUCLEI AVAILABLE IN LITTLE QUANTITIES BY MEANS OF LASER SPECTROSCOPY OF HYPERFINE STRUCTURE FOR ISOTOPES: NEW THEORETICAL SCHEME (U ,Hg)
}

\author{
A. V. Glushkov', O. Yu. Khetselius ${ }^{1}$, E. P. Gurnitskaya ${ }^{2}$, T. A. Florko ${ }^{2}$ \\ ${ }^{1}$ I. I. Mechnikov Odessa National University, Odessa \\ ${ }^{2}$ Odessa State Environmental University, Odessa
}

\begin{abstract}
SENSING OF NUCLEI AVAILABLE IN LITTLE QUANTITIES BY MEANS OF LASER SPECTROSCOPY OF HYPERFINE STRUCTURE FOR ISOTOPES: NEW THEORETICAL SCHEME (U,Hg)
\end{abstract}

A. V. Glushkov, O. Yu. Khetselius, E. P. Gurnitskaya, T. A. Florko

It is presented the the effective theoretical scheme with possibility of advancing corresponding nuclear technology for sensing different parameters for nuclei available in the little quantitites. It is based on the experimental receiving the isotope beams on the CERN ISOLDE type apparatus and the precised theoretical and laser spectroscopy empirical estimating the hyperfine structure parameters, magnetic and electric moments of a nuclei of isotopes. As example the nuclei of ${ }^{235} \mathrm{U}$ and ${ }^{201} \mathrm{Hg}$ are considered.

Key words: sensing, laser technology, hyperfine structure theory, nuclear properties

\section{Анотація}

\section{ДЕТЕКТУВАННЯ ЯДЕР ДОСТУПНИХ У МАЛИХ КІЛЬКОСТЯХ МЕТОДАМИ ЛАЗЕРНОЇ СПЕКТРОСКОПІЇ ПОНАДТОНКОІ СТРУКТУРИ ІЗОТОПІВ: НОВА ТЕОРЕТИЧНА СХЕМА (U, Hg)}

\section{О. В. Глуиков, О. Ю. Хещеліус, О. П. Гурницька, Т. О. Флорко}

Розглянута ефективна теоретична схема з можливостю удосконалення відповідної ядерної технології детектування параметрів ядер, доступних у малих кількостях. Методика базується на експериментальному отриманні пучків атомів ізотопів на установках типу CERN ISOLDE і теоретичній та емпірічній оцінці параметрів понадтонкої структури, електричного та магнітного моментів ядер ізотопів. Як приклад розглянуті ядра ${ }^{235} \mathrm{U}$ та ${ }^{201} \mathrm{Hg}$.

Ключові слова: детектування, лазерна технологія, теорія понадтонкої структури, ядерні параметри 


\title{
Аннотация \\ ДЕТЕКТРОВАНИЕ ЯДЕР ДОСТУПНЫХ В МАЛЫХ КОЛИЧЕСТВАХ МЕТОДАМИ ЛАЗЕРНОЙ СПЕКТРОСКОПИИ СВЕРХТОНКОЙ СТРУКТУРЫ ИЗОТОПОВ: НОВАЯ ТЕОРЕТИЧЕСКАЯ СХЕМА (U, Hg)
}

\author{
А. В. Глушков, О. Ю. Хецелиус, Е. П. Гурницкая, Т. А. Флорко
}

\begin{abstract}
Рассмотрена эффективная теоретическая схема с возможностью усовершенствования соответствующей ядерной технологии детектирования параметров ядер, доступных в малых количествах. Методика базируется на экспериментальном получении пучков атомов изотопов на установках типа CERN ISOLDE и прецизионной теоретической и экспериментальной (методами лазерной спектрокопии) оценке параметров сверхтонкой структуры, электрического и магнитного моментов ядер изотопов. В качестве иллюстрации рассмотрены ядра ${ }^{235} \mathrm{U}$ и ${ }^{201} \mathrm{Hg}$.
\end{abstract}

Ключевые слова: детектирование, лазерная технология, теория сверхтонкой структуры, ядерные параметры

Developing the effective nuclear schems and technologies for sensing different nuclear properties, creation of the corresponding nuclear sensors is of a great importance in the modern nuclear physics and sensor science [1-3]. Among the most important problems one could mention the studying of nuclei, which are available in the little quantities (radioactive nuclei far of the stability boundary), search of the superdence nuclei and its sensing, laser governing by parameters of the proton and other beams and sensing their characteristics etc. Such possibilities are provided by the modern laser methods and technologies [1-5]. An actual task here is developing the effective coresponding theoretical schemes and technical realization of sensing technologies on their basis. The high sensibility and resolution ability of laser spectroscopy methods allows investigating the characteristics of nuclei available in the little quantities. As an example one can mention the CERN technical device for studying the short-tlived nuclei which are obtained on the mass-separator in the line with synchrocyclotrone on $600 \mathrm{MeV}$ (ISOLDE apparatus [1]). The shocking results have been obtained in studying of the odd neutron-deficited non-stable isotopes of ${ }^{182-}$ ${ }^{190} \mathrm{Hg}$. The intensity of the ion beams of these isotopes with life tiome 1-60 min was $10^{7}-10^{9}$ ions/s. Under excitation of fluorescence by dye pulsed laser radiation the second harmonics of radiation was tuning to region of 2537A and the measurement of the hyperfine structure for this line of $\mathrm{Hg}$ was carried out during 1-2 min disposing about $10^{8}$ of the mercury isotop atoms. During transition from micleus ${ }^{186} \mathrm{Hg}$ to nucleus ${ }^{185} \mathrm{Hg}$ it has been discovered the sharp changing of the middle square of the nu- clear radius which is interpreted as sharp changing of the nuclear form (increasing of non-soherity and electic quadrupole moment) during decresing the neutrons number. In this paper it is presented the the effective theoretical scheme with possibility of advancing corresponding nuclear technology for sensing different parameters for nuclei available in the little quantitites. It is based on the experimental receiving the isotope beams on the CERN ISOLDE type apparatus (see detailed description in refs. $[1,3,4])$ and the precised theoretical and laser spectroscopy empirical estimating the hyperfine structure parameters, magnetic and electric moments of a nuclei of isotopes. As example the nuclei of ${ }^{235} \mathrm{U}$ and ${ }^{201} \mathrm{Hg}$ are considered. We carried out sensing and estimating the hyperfine structure parameters, magnetic and electric moments of a nucleus for ${ }^{235} \mathrm{U}$ and ${ }^{201} \mathrm{Hg}$. Theory of the hyperfine structure cslculation is based on developed earlier gauge-invariant QED PT with an account of correlation (interelectron interaction corrections), nuclear and QED effects. Besides, special task regarding estimating the oscillator strengths for new induced electric dipole transitions in spectra of ${ }^{201} \mathrm{Hg}$ is considered. It is well known that a change of nuclear spin under changing the neutrons number in a nucleus can influence on the selection rules. As result, the atoms of some isotopes can have the spectral lines, which are forbidden for other isotopes. They can be used for search and sensing the superdence nuclei.

Regarding calculating the hyperfine structure (HFS) parameters and nuclear quadrupole moments one could mention as follows. This task is of a great importance as it is provided by necessity of infromation ragrding these properties for creat- 
ing nuclear sensors and new nuclear technologies and also further developing the modern as atomic and as nuclear theories. From the other side, a great progress in experiments has been achieved [1-4]. Recent accurate measurements of the HFS parameters for a whole number of heavy isotopes [4] not only provide the possibility for testing the quantum electrodynamics (QED) in strong fields, but also sensing the hyperfine structure parameters of spectra for heavy atomic systems, electric charge and magnetic moment distributions inside the nucleus [5-10,20,21]. Theoretical calculations fulfilled during the last several years apart from the basis Fermi-Breit relativistic contributions also include the magnetic dipole moment distribution inside the nucleus (Bohr-Weisskopf effect) and radiative QED corrections (e.g. [1-14,16-19]). These corrections are calculated in the "external field" approximation, where the nucleus is considered as a source of an external filed for the electron [5]. In calculations of the heavy ions the well known multi-configuration (MC) Dirac-Fock (DF) approach is widely used (e.g. $[1,2,5])$. More effective method, based on the QED perturbation theory (PT) [12-14], has been developed in the series of papers [8-10,16-19]. It accounts for the relativistic, correlation effects, based on the QED qauge-invariant PT [12-14] and new effective procedures for accounting the nuclear and radiative corrections in the hyperfine structure calculation.

Let us describe the key moments of the theoretical scheme. Full details of the whole method of calculating the HFS constants can be found in [810,14,16-19]. The wave electron functions zeroth basis is found from the Dirac equation solution with potential, which includes the core ab initio potential, electric, polarization potentials of nucleus (the gaussian form for charge distribution in the nucleus is used). All correlation corrections of the second and high orders of PT (electrons screening, particle-hole interaction etc.) are accounted for [6,7]. We set the charge distribution in the nucleus by the Gaussian function:

$$
\rho(r \mid R)=\left(4 \gamma^{3 / 2} / \sqrt{\pi}\right) \exp \left(-\gamma r^{2}\right) .
$$

Here $\gamma=4 / \pi R^{2} ; R$ is an effective nucleus radius, for which the standard Z-dependence is accepted [8]. As it has been shown in many papers (e.g. $[1-5,7,11]$ and refs there), the models with the Fermi and Gauss charge distribution in a nucleus are most widespread and more correct in comparison with the model of homogeneous ball charge distribution. For example, let us mention that a difference in values of the spectra levels energies is about several $\mathrm{cm}^{-1}[1,3,4,8,16]$. The most advanced model must be based on the direct solving of the corresponding nuclear task. One could mention different versions of the shell model with the Woods-Saxon-type and spin-orbit potentials (e.g. refs.[13,17-19]).

Further let us suppose that the point-like nucleus posseses by some central potential $W(R)$. The transition to potential of the finite nucleus is realized by substituition $W(r)$ on

$$
W(r \mid R)=W(r) \int_{0}^{r} d r r^{2} \rho(r \mid R)+\int_{r}^{\infty} d r r^{2} W(r) \rho(r \mid R) .
$$

In our case the Coulomb potential for spherically symmetric density $\rho(r \mid R)$ is:

$$
V_{\text {nuсl }}(r \mid R)=-\left((1 / r) \int_{0}^{r} d r^{\prime} r^{2} \rho\left(r^{\prime} \mid R\right)+\int_{r}^{\infty} d r^{\prime} r^{\prime} \rho\left(r^{\prime} \mid R\right)\right. \text {. }
$$

Further one can write the Dirac-Fock -like equations for a multi-electron system $\{$ core- $n l j\}$. Formally they fall into one-electron Dirac equations for the orbitals $n l j$ with potential: $V(r)=2 V(r \mid c$ ore $)+V(r \mid n l j)+V_{e x}+V(r \mid R)$. It includes the electrical and polarization potentials of a nucleus. The part $V_{e x}$ accounts for exchange inter-electron interaction. The exchange effects are accounted for in the first two PT orders by the total inter-electron interaction [6,7]. The core electron density is defined by iteration algorithm within QED procedure [12]. The radiative QED (the self-energy part of the Lamb shift and the vacuum polarization contribtuion) are accounted for within the QED formalism $[8,18]$. The HFS constants are defined by the radial integrals (c.f. $[8,15])$ :

$$
\begin{aligned}
\mathrm{A}= & \left\{\left[(4,32587) 10^{-4} \mathrm{Z}^{2} \chi \mathrm{g}_{\mathrm{I}}\right] /\left(4 \chi^{2}-1\right)\right\} \times \\
& \times \int_{0}^{\infty} d r r^{2} F(r) G(r) U\left(1 / r^{2}, R\right), \\
\mathrm{B}= & \left\{7.287810^{-7} \mathrm{Z}^{3} \mathrm{Q} /\left[\left(4 \chi^{2}-1\right) \mathrm{I}(\mathrm{I}-1)\right\} \times\right. \\
\times & \int_{0}^{\infty} d r r^{2}\left[F^{2}(r)+G^{2}(r) U\left(1 / r^{2}, R\right) .\right.
\end{aligned}
$$

Here I is a spin of nucleus, $g_{I}$ is the Lande factor, $Q$ is a quadruple momentum of nucleus; radial integrals are calculated in the Coulomb units $(=3,57$ $\left.10^{20} Z^{2} \mathrm{~m}^{-2} ;=6,17410^{30} Z^{3} \mathrm{~m}^{-3}\right)$. Radial parts $F$ and $G$ of two components of the Dirac function for electron, which moves in the potential $V(r, R)+U(r, R)$, are defined by solution of the Dirac equations (PT 
zeroth order). The electric quadrupole spectroscopic HFS constant $B$ of an atomic state related to the electric field gradient $q$ and to electric quadrupole moment $e Q$ of the nucleus as: $B=e q Q / h$. So, to obtain the corresponding value of $Q$ one must combine the HFS constants data with the electric field gradient obtained in our approach from the QED PT calculation. We carried out estimating the hyperfine structure parameters, magnetic and electric moments of a nucleus for ${ }^{235} \mathrm{U}$ and ${ }^{201} \mathrm{Hg}$. In table 1 we present the values of the HFS constants for the ${ }^{201} \mathrm{Hg}$ together with available experimental results [21].

The HFS constants $\left(\mathrm{cm}^{-1}\right)$ for the ${ }^{201} \mathrm{Hg}\left({ }^{1} S_{\partial}\right)$ (nuclear spin 3/2)

\begin{tabular}{|c|c|c|c|}
\hline $\begin{array}{c}\text { HFS } \\
\text { constants }\end{array}$ & $\begin{array}{c}\text { Electron } \\
\text { Term }\end{array}$ & $\begin{array}{c}\text { Recommended } \\
{[22]}\end{array}$ & Present \\
\hline A & $6^{3} P_{2}$ & 0,3024 & 0,2902 \\
A & $6^{3} D_{3}$ & $-0,0817$ & $-0,0795$ \\
B & $6^{3} D_{3}$ & & 0,0019 \\
\hline
\end{tabular}

Further we consider the induced electric transitions in spectra of ${ }^{201} \mathrm{Hg}$. As it indicated above, a change of nuclear spin under changing the neutrons number in a nucleus can influence on the selection rules. As result, the atoms of some isotopes can have the spectral lines, which are forbidden for other isotopes. If nuclear spin makes possible the non-zeroth angle momentum of atom then the electron-nuclear interaction ca induce electrically dipole transitions for a case $J=0 \rightarrow J^{\prime}=0$. The forbidden line 2270 A $\left(6{ }^{3} P_{2} \rightarrow 6{ }^{1} S_{0}\right)$ and $2656 \mathrm{~A}\left(6{ }^{3} P_{0} \rightarrow 6{ }^{1} S_{0}\right)$ in the even isotope ${ }^{201} \mathrm{Hg}$ are the classical manifestations of this effect. Let us note that Zel'dovich and Sobelman (eg. [20]) proposed to use this effect for selective excitation of the odd and even isotopes of $\mathrm{Hg}$, $\mathrm{Sr}, \mathrm{Ba}, \mathrm{Zn}, \mathrm{Cd}$. We at first carried out the estimating the oscillator strength $g f$ for the transition $6{ }^{3} P \rightarrow$ $6^{1} S$, using the QED energy approach (eg. $[12,14,16$ $18]$ ). Our result is $g f=0,001$.

Another object of studying is the HFS of spectral line 5915,3 A of the transition $f^{3} d s^{2}{ }^{5} L_{6} \rightarrow$ $f^{3} d s p^{7} M_{7}$ for uranium ${ }^{235} \mathrm{U}$. This line is corrersponding to permitted transition from the ground state into one from many excited states. The cited transition is often used for isotopically selected excitation of the uranium atoms for industrial isotopes and nuclear isomers separation. In table 2 we present the values of the HFS constants, magnetic dipole moment $\mu$ and electric quadrupole moment $Q$ for the ${ }^{235} \mathrm{U}$ nucleus, obtained experimentally and theoretically (MCDF method) [21].
Table 2

The HFS constants, magnetic dipole moment $\mu$ and electric quadrupole moment $Q$ for the ${ }^{235} \mathrm{U}$ nucleus

\begin{tabular}{|c|c|c|c|}
\hline $\begin{array}{c}\text { HFS constants } \\
\left(\mathrm{cm}^{-1}\right), \\
\text { Moments }\end{array}$ & Experiment & $\begin{array}{c}\text { Theory } \\
\text { MCDF }\end{array}$ & $\begin{array}{c}\text { Present } \\
\text { QED PT }\end{array}$ \\
\hline $\mathrm{J}=6,-\mathrm{A}_{6}$ & 0,00125 & 0,001 & 0,00118 \\
$\mathrm{~J}=6,-\mathrm{B}_{6}$ & 0,1185 & - & 0,1138 \\
$\mathrm{~J}=7, \mathrm{~A}_{7}$ & 0,00464 & 0,0038 & 0,00437 \\
$\mathrm{~J}=7, \mathrm{~B}_{7}$ & 0,05588 & - & 0,05370 \\
$-\mu / \mu_{\mathrm{N}}$ & 0,315 & 0,289 & 0,305 \\
$Q\left(10^{-24} \mathrm{~cm}^{2}\right)$ & 6,398 & - & 6,201 \\
\hline
\end{tabular}

The key quantitative factor of agreement between theory and experiment is connected with the correct accounting for the interelectron correlations, finite size niclear, Breit and QED radiative corrections [5-14]. The well-known MCDF [3,4,20] method is not gauge-invariant one and an accounting of multi-electron correlations is not fully fulfilled, though, for example, in ref. [7] it was used the gauge-invariant local DF version in calculating the $\mathrm{N}$-like ion of $\mathrm{Bi}$. The contribution of the nuclear core-polarization effects and also the high order QED corrections can correspond the difference between theory and experiment for the nuclear moments. In conclusion let us note that we have considered and used an effective theoretical scheme for estimating the hyperfine structure parameters, magnetic and electric moments of a nucleus for ${ }^{235} \mathrm{U}$ and ${ }^{201} \mathrm{Hg}$ and reached sufficiently high accuracy. Further such theoretical estimates should be used in interpretation of the laser spectoscopy method measurement of isotope atoms spectra. In their turn the corresponding atomic beams are obtained on the massseparator in the line with synchrocyclotrone on 600 $\mathrm{MeV}$. The CERN ISOLDE apparatus is example of necessary technical devices needed for studying the short-lived, radioactive and little-quantited nuclei.

\section{References}

1. Letokhov V.S., Non-linear selective photoprocesses in atoms and molecules. - M,1987.

2. Freeman A.J., Frankel R.H., Hyperfine interactions. - N-Y.,1987.

3. Schweppe J., Belkacem A., Blumenfeld L., Clayton N., Feinberg B., Gould H., Kostroum V.E., Levy L., Misawa S., Mowst J.R. and Priuor M.H. Measurement of the Lamb shift in lithiumlike uranium $\left(\mathrm{U}^{89+}\right) / /$ Phys.Rev.Lett. - 1998-Vol.66. - P.14341437.

4. Klaft I.,Borneis S., Engel T., Fricke B., Grieser R., Huber G., Kuhl T., Marx D., Neumann R., Schroder S., Seelig P., Volker L. Precision laser spectroscopy 
of ground state hyperfine splitting of $\mathrm{H}-$ like ${ }^{209} \mathrm{Bi}^{82+} / /$ Phys.Rev.Lett. - 1994. - Vol.73. - P.2425-2427.

5. Glushkov A.V., Rusov V., Ambrosov S., Loboda A., Resonance states of compound super-heavy nucleus and EPPP in heavy nucleus collisions // New Lines of research in Nuclear physics.Eds. Fazio G.,Hanappe F.,pp.142-154, Singapore, World Sci. (2003).

6. Glushkov A.V., Malinovskaya S.V., Dubrovskaya Yu.V., Vitavetskaya L.A., Quantum calculation of cooperative muon-nuclear processes: discharge of metastable nuclei during negative muon capture// Recent Advances in Theor. Phys. and Chem. Systems. - 2006. - Vol.15. - P.301-324.

7. Khetselius O.Yu., Gurnitskaya E.P., Sensing the electric and magnetic moments of a nucleus in the $\mathrm{N}$-like ion of $\mathrm{Bi} / /$ Sensor Electr. and Microsyst. Techn. 2006. - N3. - P.35-39.

8. Bieron J., Pyykko P., Degree of accuracy in determining the nuclear electric quadrupole moment of radium//Phys.Rev. A. - 2005. - Vol.71. P.032502-1-8.

9. Bieron J., Pyykko P., Jonsson P., Nuclear quadrupole moment of ${ }^{201} \mathrm{Hg} / /$ Phys. Rev. A. - 2005. - Vol.71. P.012502-1-8.

10. Koshelev K.V., Labzowsky L.N., Tupitsyn I.I., The interelectron interaction corrections to the hfs of $2 \mathrm{p}_{3 / 2}$ state in Li-, B- and N-like Bi ions//J.Phys.B. 2004. - Vol.37. - P.843-851.

11. Ivanov L.N., Ivanova E.P., Kalinkin A.N. Nuclear and radiative effects in spectra of heavy and superheavy hydrogen-like ions//Nucl.Phys. - 1985. Vol.42. - P.355-362.

12. Ivanova E.P., Ivanov L.N., Glushkov A.V., Kramida A.E. High order corrections in the Relativistic Perturbation Theory with the model Zeroth Approximation, Mg-like and Ne-like ions //Phys.Scripta. 1985. - Vol.32(4). - P.512-524.
13. A.V.Glushkov, S.V.Ambrosov, A.V.Loboda A.V., Yu.G.Chernyakova, A.A.Svinarenko, O.Yu.Khetselius, QED calculation of the superheavy elements ions: energy levels, radiative corrections and hfs for different nuclear models// Nucl. Phys.A.: Nucl.and Hadr. Phys. - 2004. - Vol.734. - P.21-28.

14. Khetselius O.Yu., Hyper fine structure of radium// Photoelectronics. - 2005. - N14. - P.83-85.

15. Gurnitskaya E.P., Khetselius O.Yu., Sensing the hyperfine structure and nuclear quadrupole moment for radium// Sensor Electr. and Microsyst. Techn. 2006. - N2. - P.25-29.

16. Glushkov A.V., Khetselius O.Yu., Gurnitskaya E.P., QED calculation of the fine and hfs parameters for heavy ions: modified ISAN-Superatom Program Package// Preprint of I.I.Mechnikov Odessa National Univ.,IP: Ph-L-4. - Odessa-2003.

17. Glushkov A.V., Ivanov L.N. Radiation Decay of Atomic States: atomic residue and gauge non-invariant contributions // Phys. Lett.A. - 1992. Vol.170(1). - P.33-38.

18. Glushkov A.V. Negative Ions of inert Gases// JETP Lett. - 1992. - Vol.55(2). - P.97-100.

19. Glushkov A.V., Ambrosov S.V., Khetselius O.Yu., Loboda A.V., Gurnitskaya E.P., QED calculation of heavy multicharged ions with account for the correlation, radiative and nuclear effects// Recent Adv. in Theor. Phys. \&Chem. Systems. - 2006. - Vol.15. P. $285-300$

20. Glushkov A.V., Malinovskaya S.V., Gurnitskaya E.P., Khetselius O.Yu.,Dubrovskaya Yu.V., Consistent quantum theory of the recoil induced excitation and ionization in atoms during capture of neitron// J.Phys.CS. - 2006. - Vol.35. - P.425-430.

21. Sobel'man I.I. Introduction to theory of atomic spectra. - Moscow: Nauka. - 1977.

22. Radtsig A.A.,Smirnov B.M., Parameters of atoms and ions. - Moscow, 1986. 